\title{
Rapid Synthesis of Yellow Graphite Oxide - One-Step Electrochemical Oxidation of Graphite in Organic Solvents
}

\author{
Andreas Schedy ${ }^{*}$, Beau Matyas, Marco Oetken \\ Department of Chemistry, Physics, Technology and their teaching methodologies, \\ University of Education Freiburg, Kunzenweg 21, 79117 Freiburg im Breisgau, German \\ *Corresponding author: andreas.schedy@ph-freiburg.de
}

Received January 16, 2019; Revised February 21, 2019; Accepted March 27, 2019

\begin{abstract}
Graphite oxide is the intermediate in the synthesis of the so-called "miracle material" of the 21 st century, graphene. The synthesis of highly oxidized, yellow graphite oxide is hitherto only possible via partially toxic and explosive wet-chemical processes. Therefore, the implementation of the topic graphene in school and university lessons was not possible. Due to the existing risks and the long synthesis time, the currently prevalent synthesis methods of graphite oxide are a major problem not only for teaching but also for scientific research. The authors present a novel electrochemical synthesis process of highly oxidized, yellow graphite oxide, which completely avoids the use of corrosive or toxic substances. The synthesis time is only a few minutes and the preparation of the material can be easily carried out. Therefore, Graphene can now be easily synthesized and taught in school and university.
\end{abstract}

Keywords: graphene, graphene oxide, structure-property relationships

Cite This Article: Andreas Schedy, Beau Matyas, and Marco Oetken, "Rapid Synthesis of Yellow Graphite Oxide - One-Step Electrochemical Oxidation of Graphite in Organic Solvents." World Journal of Chemical Education, vol. 7, no. 2 (2019): 109-119. doi: 10.12691/wjce-7-2-11.

\section{Introduction}

The rapid storage of electrical energy and the development of efficient energy storage are currently global goals of science, technology and politics. Due to its special physical properties (better electrical conductivity than copper, harder than steel, very large active surface [1]), graphene is regarded as a forward-looking material and is therefore currently the focus of research. Graphene is the two-dimensional modification of carbon and can be described more easily as a one-atom thick layer of a three-dimensional graphite complex. In graphite, the individual graphene layers are held together by van der Waals interactions [2].

A major challenge currently exists in the synthesis of graphene. Graphene is produced on a laboratory scale in a three-step process in which graphite is the starting material. In a first step, graphite is oxidized to form oxygen-containing functional groups on the individual graphene layers. The formation of the functional groups leads to an increase of the layer spacing between the graphene layers, and the van der Waals interactions between the graphene layers are already strongly attenuated. By subsequent ultrasound treatment, the weak interactions can be overcome. This results in individual oxidized graphene layers, also called graphene oxide.
Through a subsequent reduction process (thermal reduction $[3,4]$, chemical reduction [5]), the functional groups of graphene oxide can be cleaved to give graphene.

Depending on the process, during oxidation a different number of oxygen-containing functional groups are formed on the graphene layers. Strong oxidation of graphite is desirable from a technical perspective, as it greatly shortens the exfoliation process. The more functional groups that form on the graphene layers, the more polar they become. The van der Waals interactions between the layers are thereby automatically greatly attenuated and the layers can then be easily separated from each other. The highly oxidized graphite oxide is very interesting - not only from a technical, but also from a didactic perspective. Graphite oxide has a different color depending on the degree of oxidation. While it has a black color in lightly oxidized states, it first assumes a green and then a yellow color in higher oxidation states [6]. Due to the color change, students can clearly distinguish the gray starting material graphite, the yellow intermediate graphite oxide, and the black graphene - and thus understand the synthesis process.

\subsection{Wet-chemical Graphite Oxide Synthesis}

The currently predominant synthesis method of graphite oxide follows the Hummers method [7]. To oxidize graphite, a mixture of potassium permanganate, 
concentrated sulfuric acid and sodium nitrate is used. The oxidizing power of this mixture is so strong that the final product is the yellow, highly oxidized graphite oxide.

The method of Hummers and the other wet-chemical synthesis methods for yellow graphite oxide according to Brodie [8] and Staudenmaier [9] are not suitable for school and university education. These processes lead to explosive intermediates which, in combination with the concentrated acids, present too great a danger potential. Furthermore, these methods require a very long reaction time and it takes a long time to rid the graphite oxide from the oxidizing agents and acids.

\subsection{The Electrochemical Synthesis of Yellow Graphite Oxide}

Pei et. Al. presented a completely new synthesis of yellow graphite oxide based on an electrochemical synthesis pathway [10]. The starting material is a graphite foil. In a first step, it is switched in concentrated sulfuric acid as a positive pole. As a result, hydrogen sulfate ions intercalate into the graphite and completely occupy the interstices between the graphene layers. This Stage-1graphite intercalation compound (GIC) has the formula $\mathrm{C}_{21-28}{ }^{+} * \mathrm{HSO}_{4}{ }^{-} * 2,5 \mathrm{H}_{2} \mathrm{SO}_{4}$ and has a typical deep blue color. The intercalation of the hydrogen sulfate ions increases the layer spacing between the individual graphene layers. As a result, in a second step the oxidizing agent can penetrate between the layers. For this purpose, the GIC is transported in a semi-concentrated sulfuric acid and further switched as positive pole. The oxidative agent in this process is water. The hydrogen sulphate ions are hydrated in the $50 \%$ sulfuric acid. During intercalation, ions inject water molecules into graphite. Due to the applied voltage of $5 \mathrm{~V}$, the water is decomposed electrochemically. The decomposition products of the water react with the graphite, forming covalent bonds and forming oxygen-containing functional groups on the graphite. The oxidative effect can be traced by an abrupt staining of the blue GIC to the yellow graphite oxide. Within a few minutes, the entire graphite foil immersed in the electrolyte is converted to the yellow graphite oxide.

This new synthesis method is more environmentally friendly and has a lower risk potential than the Hummers, Brodie or Staudnmaier synthesis pathways. However, the use of concentrated sulfuric acid in the school experiment is questionable due to the risk of chemical burns. In the following, we present a variant of this two-step electrochemical synthesis process, which dispenses with the concentrated sulfuric acid in the first step. This makes it possible to produce yellow graphite oxide with schoolrelevant means for the first time. Furthermore, for the first time we present an electrochemical one-step process, which drastically simplifies the synthesis process of highly oxidized graphite oxide. This completely dispenses with the use of acids, delivers high yields within a very short time and can be scaled up at will. This makes it very suitable for school lessons, but also for technical applications. In an ultrasonic bath, the graphite oxide is converted into graphene oxide in a short time. The self-produced graphene oxide can then be easily reduced to graphene. In further experiments, the newly created properties of graphene oxide and graphene can be clarified.

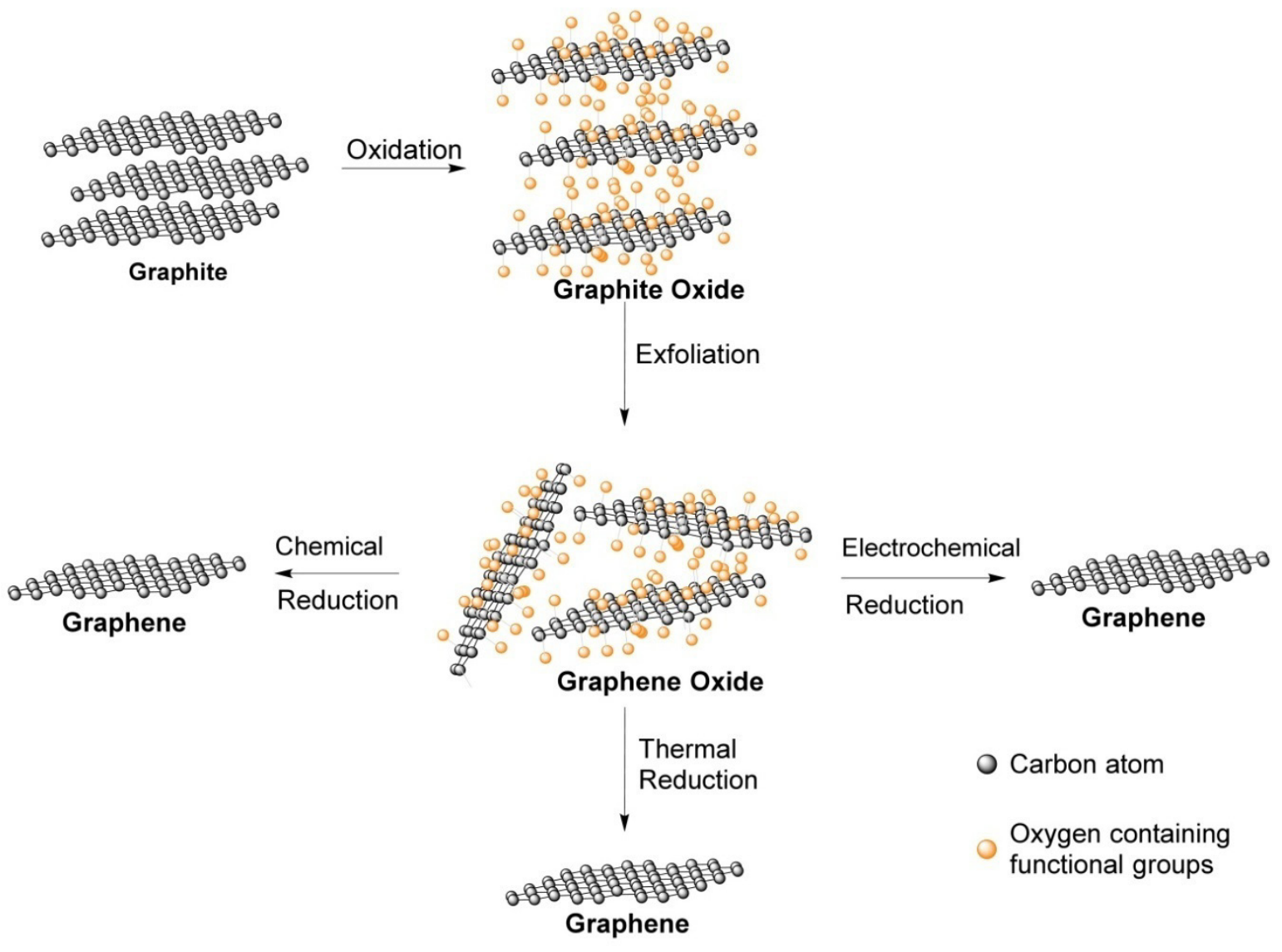

Figure 1. Route for the synthesis of graphene oxide and graphene 

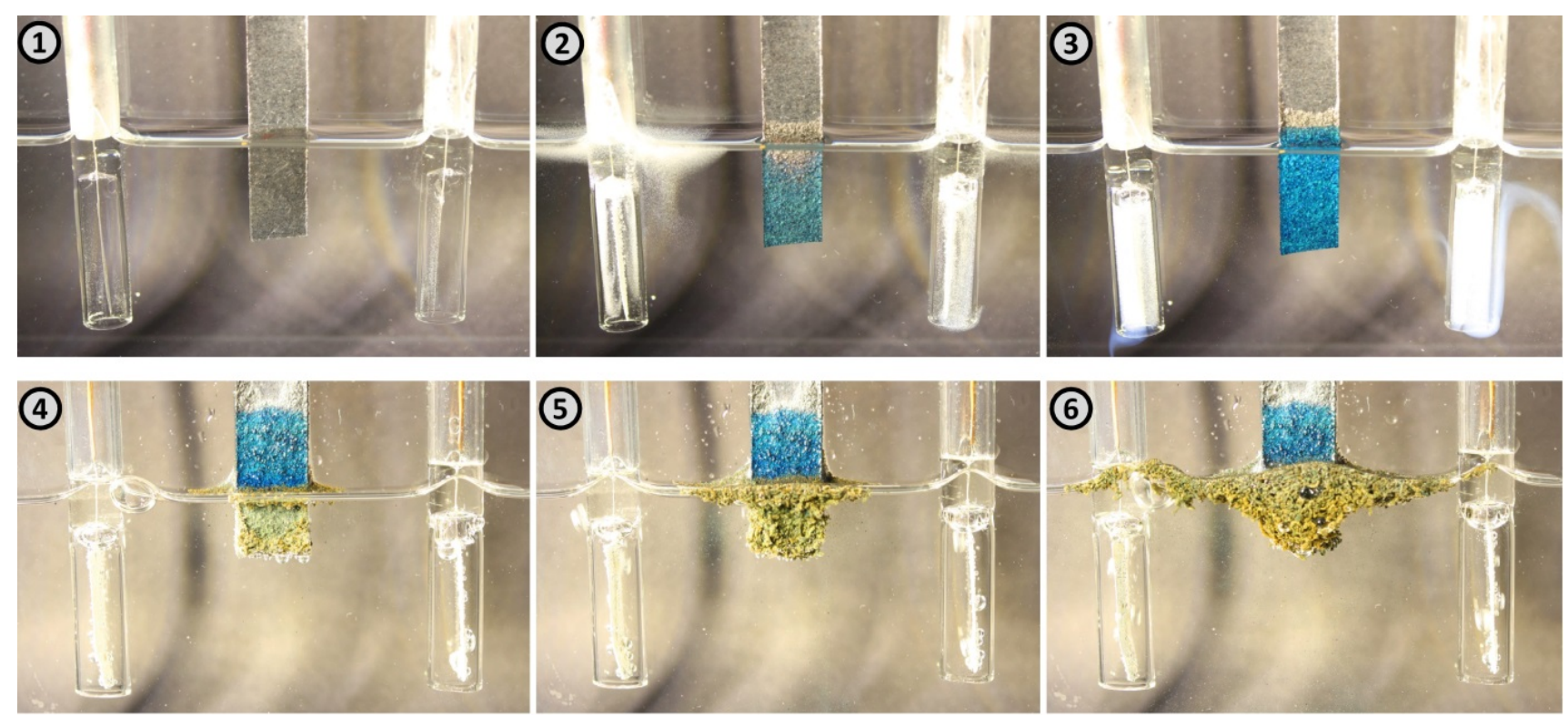

Figure 2. Synthesis of yellow graphene oxide according to Pei et al. Image 1-3: Intercalation of hydrogen sulfate ions into the graphite and formation of the blue Stage 1 graphite intercalation compound (GIC). Image 4-6: Transfer the graphite intercalation compound to $50 \%$ sulfuric acid at 5 volts. By oxidative processes, the yellow graphite oxide forms

\section{Experimental Materials and Procedures}

\subsection{General and Safety Precautions}

Chemicals were purchased from Sigma Aldrich. All selected materials are commercially available and can be obtained easily. The experiments are designed so that they can be carried out by the students. The organic solvents used are highly flammable, so sources of ignition must be kept away from the experiments. The experiments may only be performed using safety clothing (such as goggles $\&$ gloves). The experiments can be carried out at room temperature and in room air.

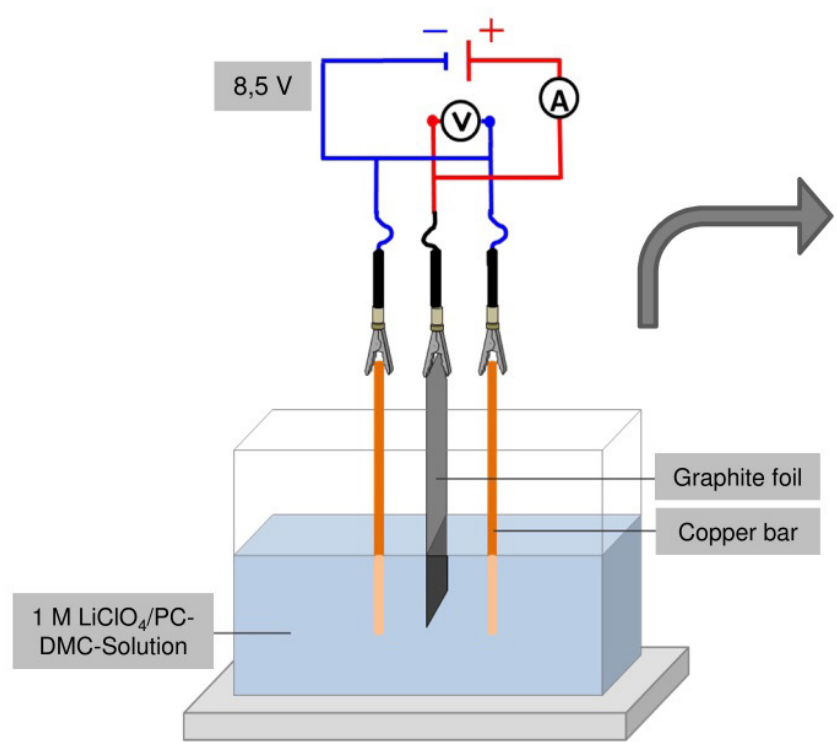

\subsection{The Electrochemical Synthesis of Yellow Graphite Oxide in a Two-step Process}

Materials and chemicals: $2 \mathrm{x}$ copper rods, $2 \mathrm{x}$ Ptelectrodes, graphite foil $(5 \mathrm{~cm} \times 1 \mathrm{~cm} \times 0.15 \mathrm{~mm}), 2 \mathrm{x}$ vessels, e.g. small beakers or glass cuvettes, $2 \mathrm{x}$ voltage supplies, alligator clips, connection cables, electrolytic solution A (lithium perchlorate, propylene carbonate (PC), dimethyl carbonate (DMC)), sulfuric acid (50\%).

Preparation of Electrolytic Solution A: $100 \mathrm{ml}$ of a 1 molar lithium perchlorate solution in a 1 to 4 mixture of propylene carbonate and dimethyl carbonate is prepared by dissolving $10.6 \mathrm{~g}$ of lithium perchlorate in a mixture of $20 \mathrm{ml}$ of propylene carbonate and $80 \mathrm{ml}$ of dimethyl carbonate.

Figure 3. Schematic experimental setup for the school-relevant electrochemical 2-step synthesis of highly oxidized graphite oxide. After 30 minutes of electrolysis in the organic electrolyte, the graphite foil is transferred to the $50 \%$ sulfuric acid 
The electrochemical synthesis of yellow graphite oxide is achieved in a two-step process. The graphite foil extends approx. $2 \mathrm{~cm}$ deep into the electrolyte solution and is switched as positive pole. Two copper rods serve as negative pole. The applied voltage is 8.5 volts.

After 30 minutes, the graphite foil is removed from the organic electrolyte and transferred to the semi-concentrated sulfuric acid. Already when transferring to the acid, a voltage of 4 volts must be present. The graphite foil will continue to be switched as positive pole. The counter electrode used here are two platinum electrodes. The synthesis is complete as soon as the entire electrode immersed in the acid has decomposed.

\subsection{Targeted Oxidation of Graphite in Organic Electrolyte by Spraying with Water}

Materials and chemicals: beaker, graphite foil $(7 \mathrm{~cm} \mathrm{x}$ $1 \mathrm{~cm} \times 0.15 \mathrm{~mm})$, copper sheet $(7 \mathrm{~cm} \mathrm{x} 1 \mathrm{~cm})$, voltage supply, connection cables, alligator clips, syringe, hollow needle, electrolytic solution B (sodium perchlorate, propylene carbonate, dimethyl carbonate), distilled water.

Preparation of Electrolytic Solution B: $100 \mathrm{ml}$ of a 1 molar sodium perchlorate solution in a 1 to 4 mixture of propylene carbonate and dimethyl carbonate is prepared by dissolving $12.4 \mathrm{~g}$ of sodium perchlorate in a mixture of $20 \mathrm{ml}$ of propylene carbonate and $80 \mathrm{ml}$ of dimethyl carbonate.

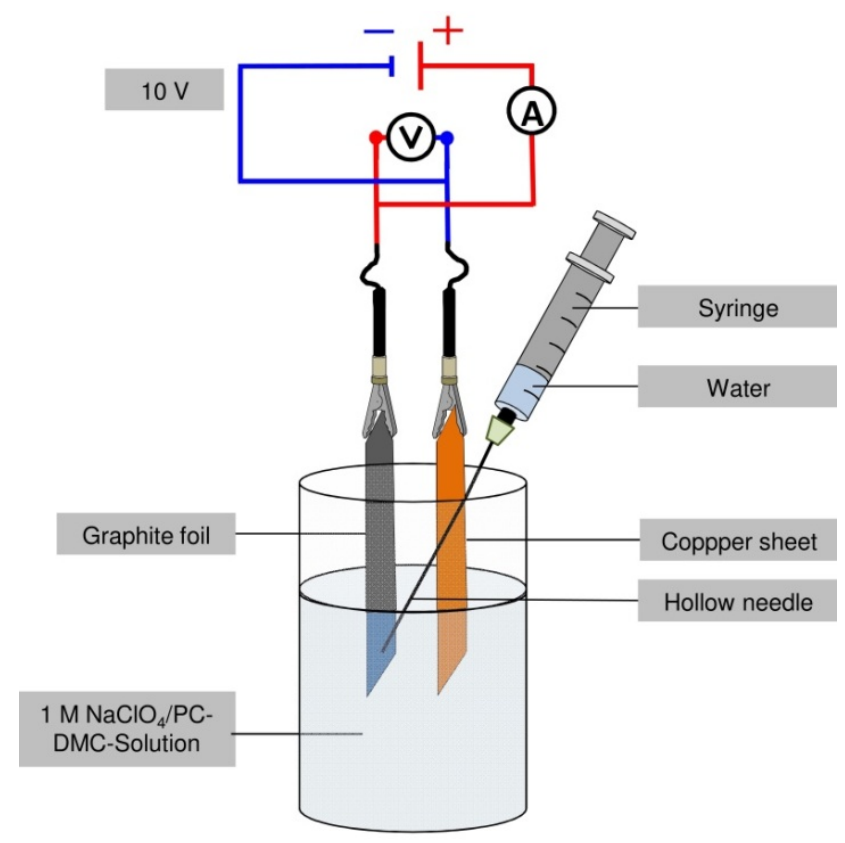

Figure 4. Schematic experimental setup for the targeted oxidation of graphite. The blue graphite intercalation compound is sprayed with water in a targeted manner

The graphite foil extends approx. $2 \mathrm{~cm}$ deep into the electrolyte solution and is switched as positive pole. The negative pole is a copper sheet. To make the blue GIC 10 volts are applied. After 30 seconds, a syringe is used to spray water onto the blue graphite surface. Caution: The hollow needle must not touch the graphite foil; otherwise chemical reactions will take place on the hollow needle. It is recommended to fix the syringe and cannula with a laboratory stand before applying the voltage. The end of the cannula is already directed to the graphite foil. This ensures a safe execution of the experiment.

\subsection{Electrochemical Synthesis of Yellow Graphite Oxide in a One-step Process}

Materials and chemicals: beaker, graphite foil $(7 \mathrm{~cm} \mathrm{x}$ $1 \mathrm{~cm} \mathrm{x} 0.15 \mathrm{~mm})$, copper sheet $(7 \mathrm{~cm} \mathrm{x} 1 \mathrm{~cm})$, voltage supply, connection cables, alligator clips, vacuum pump, Büchner funnel, Büchner flask, vacuum hose, round filter ( $\varnothing=70 \mathrm{~mm}$ ), electrolytic solution $\mathrm{C}$ (sodium perchlorate, propylene carbonate, dimethyl carbonate, distilled water), distilled water, ultrasonic bath (e.g. Sonorex RK 31H), round bottom flask.

Preparation of Electrolytic Solution C: $100 \mathrm{ml}$ of a 1 molar sodium perchlorate solution in a 1 to 4 mixture of propylene carbonate and dimethyl carbonate is prepared by dissolving $12.4 \mathrm{~g}$ of sodium perchlorate in a mixture of $20 \mathrm{ml}$ of propylene carbonate and $80 \mathrm{ml}$ of dimethyl carbonate. Subsequently, $40 \mathrm{ml}$ of the sodium perchlorate solution are mixed with $2 \mathrm{ml}$ of water.

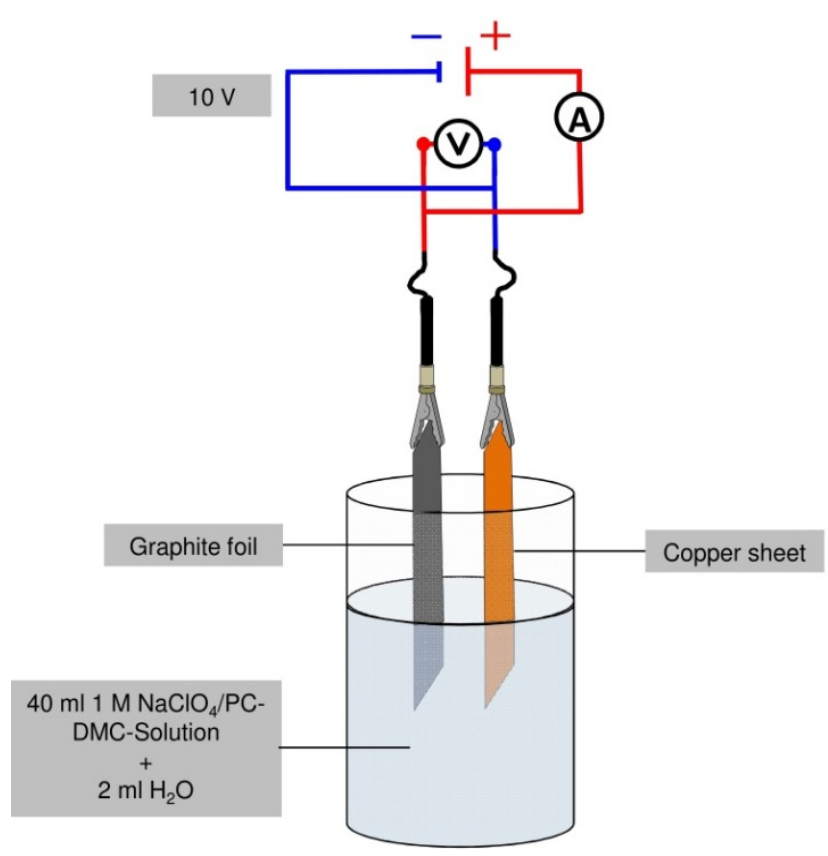

Figure 5. Schematic experimental setup for the electrochemical one-step synthesis of highly oxidized graphite oxide

The graphite foil extends approx. $2 \mathrm{~cm}$ deep into the electrolyte solution and is switched as positive pole. The negative pole is a copper sheet. The applied voltage is 10 volts. The synthesis is complete as soon as the entire electrode immersed in the electrolyte has decomposed. In order to free the reaction product from the organic solvents, it is then filtered off with suction on a filter paper and washed with about $200 \mathrm{ml}$ of distilled water. Subsequently, the product is transferred again into an aqueous suspension. To establish graphene oxide, the graphite oxide suspension is filled into a round bottom flask and placed in the ultrasonic bath for 30 minutes. 


\section{Results and Discussion}

\subsection{The Electrochemical Synthesis of Yellow Graphite Oxide in a Two-step Process}

The synthesis of yellow graphite oxide succeeds in a two-step process. First, a graphite foil is switched as a positive pole in the electrolytic solution A and a voltage of 8.5 volts is applied. The counter electrode is a copper rod. The graphite foil is deprived of electrons. For charge balance, perchlorate ions diffuse to the graphite foil and are intercalated [11].

$$
\mathrm{xC}+\mathrm{ClO}_{4}^{-} \rightarrow \mathrm{C}_{\mathrm{x}}{ }^{+} \mathrm{ClO}_{4}{ }^{-}+\mathrm{xe}^{-} \text {. }
$$

At the copper rod elemental lithium is formed.

$$
\mathrm{x} \mathrm{Li}{ }^{+}+\mathrm{xe}^{-} \rightarrow \mathrm{x} \mathrm{Li} .
$$

The intercalation of the perchlorate ions in graphite proceeds in a step formation. Characteristic is the blue color of the graphite, which forms as soon as all spaces between the graphene layers are filled with ions. Once the graphite is completely filled with ions, there is a ratio of one perchlorate ion to 24 carbon atoms $\left(\mathrm{C}_{24}{ }^{+}\left(\mathrm{ClO}_{4}{ }^{-}\right)_{1}[12]\right.$.
Thus, this compound has the same intercalation ratio as can be achieved in concentrated sulfuric acid by the intercalation of hydrogen sulfate ions. However, the GIC can be achieved entirely without hazards in the organic electrolytic solution. This variant is therefore very well suited for school lessons.

The formation of this intermediate plays a major role in the synthesis of highly oxidized graphite oxide. During the formation of the GIC, no electron transfer between electrolyte and electrode takes place. Through any anion that pushes between the graphene layers, graphite gets another positive charge. The graphite becomes strongly positively polarized in the course of intercalation and thus highly reactive. This strongly positively polarized graphite favors the formation of the oxygen-containing functional groups on the individual graphene layers in the further oxidation process [13]. The intercalation of the ions further causes a swelling of the graphite, whereby the layer spacing between the individual graphene layers increases significantly. This can ensure that in a later phase of the process, the oxidant can get between all layers and cause oxidation of the entire carbon [6]. As can be seen on the appearance of the blue color, the GIC forms very quickly on the graphite surface.
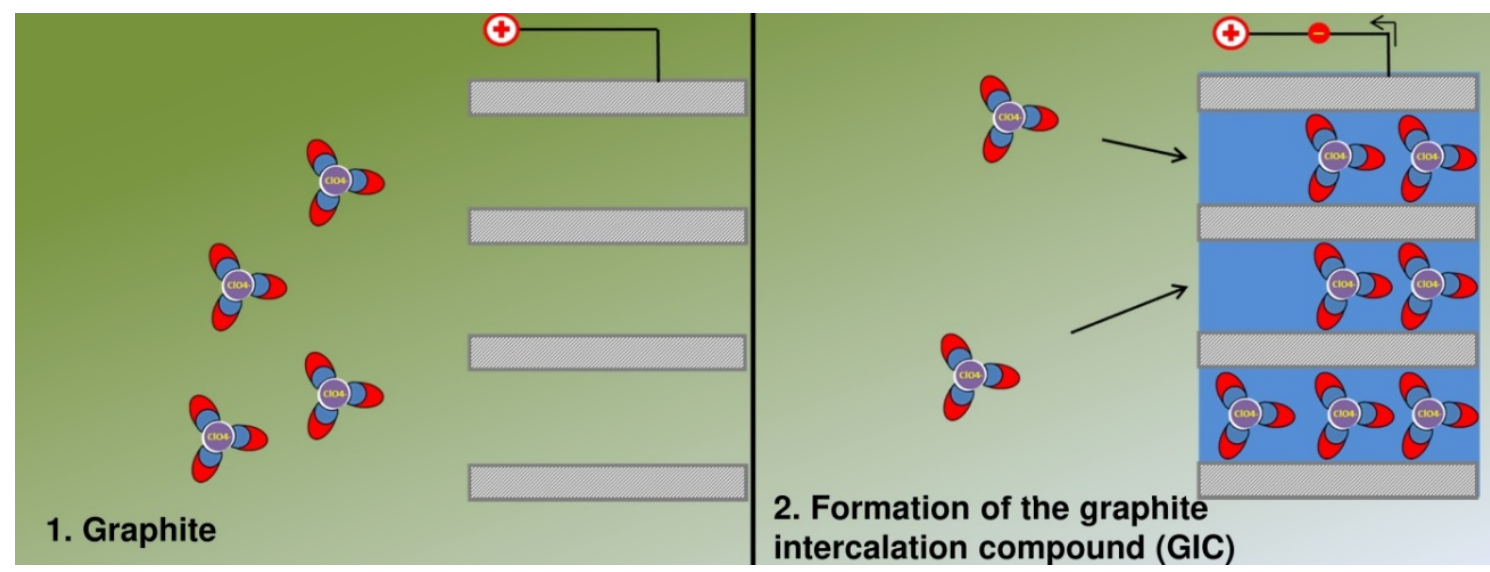

Figure 6. Schematic representation of the intercalation of solvated perchlorate ions in graphite from an organic electrolyte
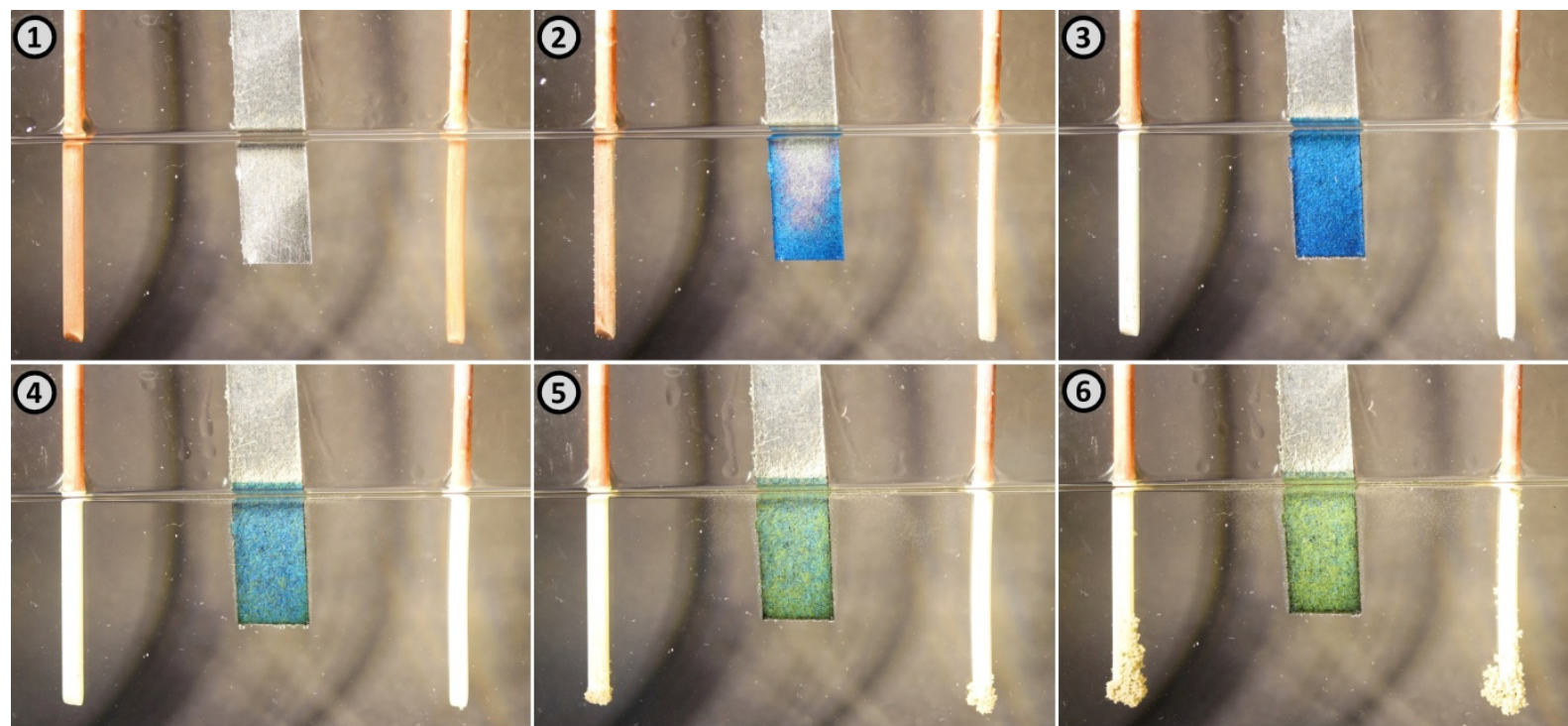

Figure 7. Electrochemical intercalation of perchlorate ions in graphite. Blue coloration of graphite due to the formation of the GIC. Image 1-6: Observations after 0 seconds, 5 seconds, 30 seconds, 5 minutes, 10 minutes, 20 minutes 

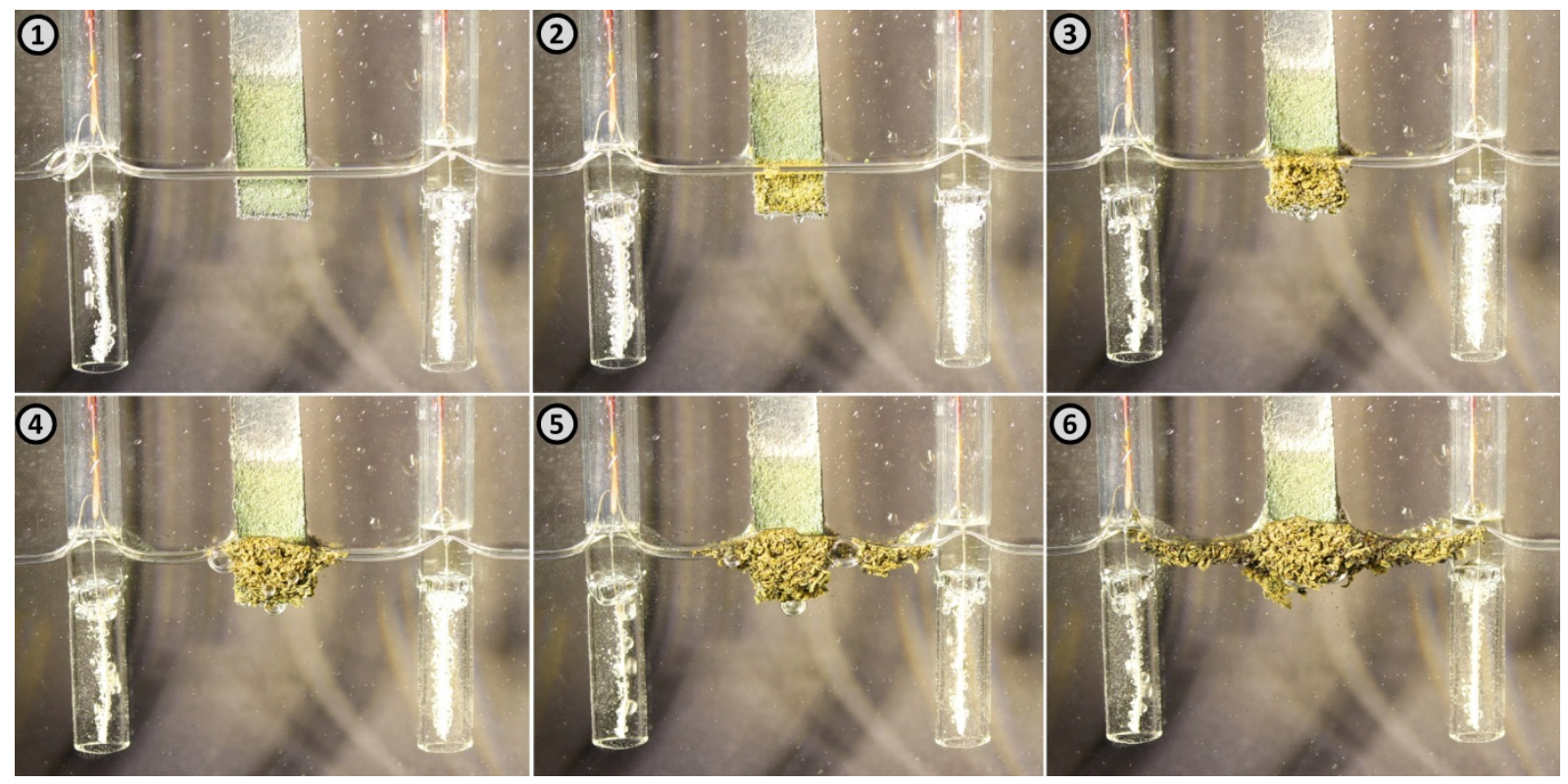

Figure 8. Transferring the GIC into a 50\% sulfuric acid. Electrochemical oxidation and exfoliation of graphite. Image 1-6: Observations after 0 seconds, 1 minutes, 3 minutes, 5 minutes, 7 minutes, 15 minutes

The intercalation of the further inner regions of the graphite foil takes more time, which is why an electrolysis time of 30 minutes is recommended.

By subsequently transferring the graphite foil into the semi-concentrated sulfuric acid, the oxidation process is initiated. After a short time, the graphite foil assumes the deep yellow color typical of highly oxidized graphite oxide. Likewise, a gas evolution is observed on the graphite foil, which causes an exfoliation of the material.

As a mechanism leading to high oxidation of graphite, the following is proposed. In the first step, the graphite is deprived of electrons, thereby strongly shifting the potential of the graphite foil into the positive region. For charge balance, perchlorate ions intercalate into the graphite until the spaces between the graphene layers are completely filled.

In the second step, the graphite foil is transferred into $50 \%$ sulfuric acid. The oxidation potential of the positively polarized graphite is very high. Upon contact, a reaction takes place immediately with the water molecules present in the sulfuric acid. In the ongoing redox reaction, the water releases electrons to the graphite.

$$
\begin{gathered}
2 \mathrm{H}_{2} \mathrm{O} \rightarrow \mathrm{O}_{2}+4 \mathrm{H}^{+}+4 \mathrm{e}^{-} \\
4 \mathrm{C}_{\mathrm{x}}{ }^{+} \mathrm{ClO}_{4}{ }^{-}+4 \mathrm{e}^{-} \rightarrow 4 \mathrm{C}+\mathrm{ClO}_{4}{ }^{-} .
\end{gathered}
$$

To restore electroneutrality in the graphite matrix, a perchlorate anion is removed from the graphite matrix. The previously formed graphite intercalation compound thus dissolves directly on contact with water.

When transferred into the sulfuric acid, the graphite foil is further switched as a positive pole and thus the graphite continues to be deprived of electrons. This triggers 2 processes: on the one hand, water is electrochemically decomposed at the electrode surface to produce oxygen; on the other hand, hydrogen sulfate ions diffuse to the graphite. The hydrogen sulfate anions can intercalate into the graphite and occupy the space of the formerly intercalated perchlorate ion. So there is an exchange of ions. In the diluted sulfuric acid, the hydrogen sulfate ions are surrounded by a hydrate shell. During intercalation, they introduce water molecules between the graphene layers [14]. The introduced water molecules are electrochemically decomposed at the applied voltage of $4 \mathrm{~V}$. However, the expected oxygen evolution and exfoliation of the graphite is very weak. The reason for this is that the strongly positively polarized, highly reactive graphite reacts with the decomposition products of the water.

In the GIC, the graphite is already in its maximum oxidized state. If the graphite is further electrochemically oxidized in the presence of water, "overoxidation" may occur. Overoxidation in this case means that the maximum possible charge transfer to the conjugated pi-electron system is exceeded. The overoxidation leads to the formation of oxidation products with covalent bonds [15].

(1)

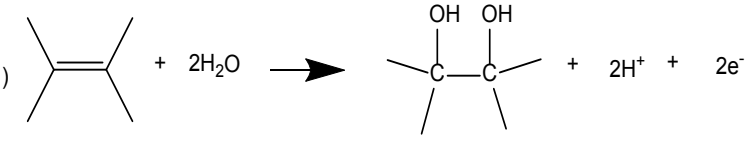

(2)<smiles>CC(C)(O)C(C)(C)O</smiles><smiles>CC1(C)OC1(C)C</smiles>

(3)<smiles>CC(C)(O)C(C)(C)O</smiles><smiles></smiles>

(4)
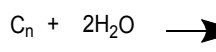

$\mathrm{C}_{\mathrm{n}-1} \mathrm{COOH}+3 \mathrm{H}^{+}+3 \mathrm{e}^{-}$

(5)

$C+2 \mathrm{H}_{2} \mathrm{O}$

$\mathrm{CO}_{2}+4 \mathrm{H}^{+}+4 \mathrm{e}^{-}$

(6)

$2 \mathrm{H}_{2} \mathrm{O}$

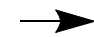

$\mathrm{O}_{2}+4 \mathrm{H}^{+}+4 \mathrm{e}^{-}$

Figure 9. Possible processes in the anodic oxidation of graphite (1-5), as well as oxidation of water molecules from the solvation shell, edited according to $[16,17]$ 


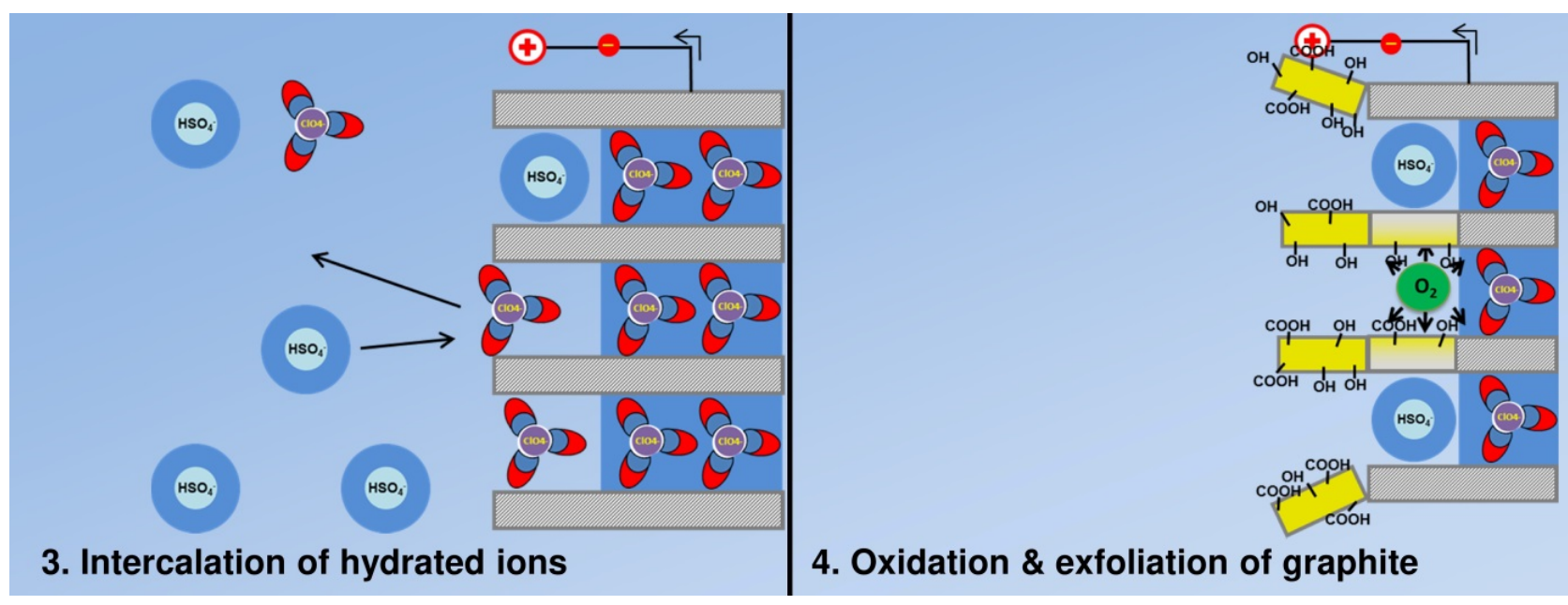

Figure 10. Schematic representation of the electrochemical oxidation process of graphite in $50 \%$ sulfuric acid. Left: Hydrated hydrogen sulfate ions intercalate between the graphene layers. Right: Graphite reacts with the decomposition products of water, forming oxygen-containing functional groups. The resulting oxygen effects a pressure increase inside the electrode, causing the oxidized areas to flake off

The newly formed oxygen-containing functional groups disrupt the delocalized pi-electron system of graphite, and the electrical conductivity is lost. The graphite oxide is thus an electrical non-conductor [18]. As a result, the graphite cannot be further oxidized electrochemically from here on. In addition to the electrochemical oxidation, the graphite undergoes further reactions with the radical decomposition products of the water, which oxidize the graphite even higher [13]. It is well known that the anodic decomposition of water produces radical intermediates before the release of gaseous oxygen [19].

$$
\begin{gathered}
\mathrm{H}_{2} \mathrm{O} \rightarrow \mathrm{OH}_{(\mathrm{ad})}^{\cdot}+\mathrm{H}^{+}+\mathrm{e}^{-} \\
\mathrm{OH}_{(\mathrm{ad})}^{-} \rightarrow \mathrm{O}_{(\mathrm{ad})}^{\cdot}+\mathrm{H}^{+}+\mathrm{e}^{-} \\
\mathrm{O}_{(\mathrm{ad})}^{\cdot}+\mathrm{H}_{2} \mathrm{O} \rightarrow \mathrm{OOH}_{(\mathrm{ad})}+\mathrm{H}^{+}+\mathrm{e}^{-} \\
\mathrm{OOH}_{(\mathrm{ad})}^{\cdot} \rightarrow \mathrm{O}_{2} \uparrow+\mathrm{H}^{+}+\mathrm{e}^{-} .
\end{gathered}
$$

Even after the conductivity of the graphite has been lost, the highly reactive radicals can undergo reactions with the graphite and further oxidize it [10]. The graphite assumes a deep yellow color through this oxidation process, as is typical of the high oxidation states of graphite. The small amount of oxygen that arises between the graphene layers causes a moderate pressure increase in the electrode. As a result, a slow but continuous exfoliation of the material takes place and the oxidized areas burst.

To obtain highly oxidized graphite, the interplay between the removal of perchlorate and the incorporation of hydrated hydrogen sulfate ions must work perfectly. Ideally, a perchlorate ion is first removed from the graphite matrix. Subsequently, a hydrated hydrogen sulfate ion enters the graphite and the described oxidation processes occur. Due to the small amounts of gaseous oxygen which arise during the oxidation of the water, a moderate expansion of the graphite takes place. As a result, areas of the graphite further in the center come into contact with water. There, the processes are repeated, whereby the graphite is slowly oxidized from outside to inside. The concentration of sulfuric acid, and thus its content of water, is of the utmost importance for this mechanism. At a higher water content, the highly water-prone GIC dissolves increasingly before it comes to the incorporation of hydrated ions. In this process, the graphite loses its positive polarization, which is why it cannot come or only occasionally comes to over-oxidation in the following step. At higher water content, the introduced water molecules are converted mainly to oxygen, whereby the exfoliation of the material is enhanced. The increased exfoliation causes a cleavage of non-oxidized or only slightly oxidized areas. As a result, low-concentration sulfuric acid does not lead to the highly oxidized graphite oxide [20]. A higher concentration of sulfuric acid $(>60 \%)$ also leads to lower oxidation of graphite. In higher concentrated acids, little water is contained in the system and the removal of the perchlorate ions is inhibited. As a result, the hydrated ions can only occasionally penetrate into the inner regions of the graphite foil. In the semiconcentrated sulfuric acid, the ideal reaction conditions prevail, resulting in the highly oxidized graphite oxide, which assumes a typical yellow color.

\subsection{Targeted Oxidation of Graphite in the Organic/Aqueous Electrolyte.}

The formation of the blue GIC, which is usually achieved in concentrated acids, is a central intermediate step in the synthesis of highly oxidized graphite oxide. The use of an organic electrolyte is a safe alternative to the concentrated acids in the variants described above. The formation of the blue GIC is followed by oxidation of the graphite in dilute sulfuric acid, with the blue graphite electrode becoming distinctly yellow. With this electrochemical 2-step process, a synthetic procedure could be presented, which is harmless and thus suitable for school lessons.

Surprisingly, after about 20 minutes of electrolysis in the organic electrolyte, the graphite foil changes its color from blue to yellow, which is an indication of a strong oxidation on graphite (compare Figure 7, 4-6). Water is the oxidant in the electrochemical oxidation process of graphite. The observation is surprising since the 
intercalation of the perchlorate ions is carried out in the anhydrous organic electrolyte. However, low water inputs can already occur during the production process of the organic electrolyte under the given working conditions. The strongly hygroscopic salts and solvents are opened in the room air, whereby water entry is unavoidable. The experiments are carried out in the normal ambient air and not under protective gas in so-called glove boxes, whereby further water inputs by the air-humidity cannot be excluded. These small amounts of water lead to a superficial oxidation of the graphite by the electrochemical processes already described.

This phenomenon shows that it is possible to oxidize the graphite in the organic electrolyte by the presence of minute amounts of water. In the following, it had to be checked whether the water was actually responsible for the oxidation of the graphite. First, we made the GIC in the organic electrolyte. After 30 seconds, we deliberately brought water to the blue graphite surface using a syringe. The electrode turns yellow upon contact with water in accordance with the theory. This confirms that the water inputs in the organic electrolyte are responsible for the oxidation of the graphite. The sudden discoloration of the electrode indicates that the oxidation process takes place very quickly in the presence of water. After the water has mixed with the organic electrolyte, the entire electrode immersed in the electrolyte assumes a yellow color (see Figure 12-5). Elemental sodium is formed on the copper sheet. By contact with water, the sodium dissolves in a bubbly manner, whereby hydrogen is produced.

Amazingly, in the course of another 30 minutes, the areas in the center of the graphite foil also turn yellow and burst. As already mentioned in section 3.1, the blue GIC is the basis for the synthesis of highly oxidized graphite oxide. Since the intercalation time in this experiment was only 30 seconds, the intercalation of perchlorate ions into the interior of the graphite foil has not yet taken place. This observation indicates that, given a suitable ratio of organic electrolyte to water, the processes of intercalation to the blue \& highly reactive graphite intercalation compound and the oxidation to yellow graphite oxide occur simultaneously.

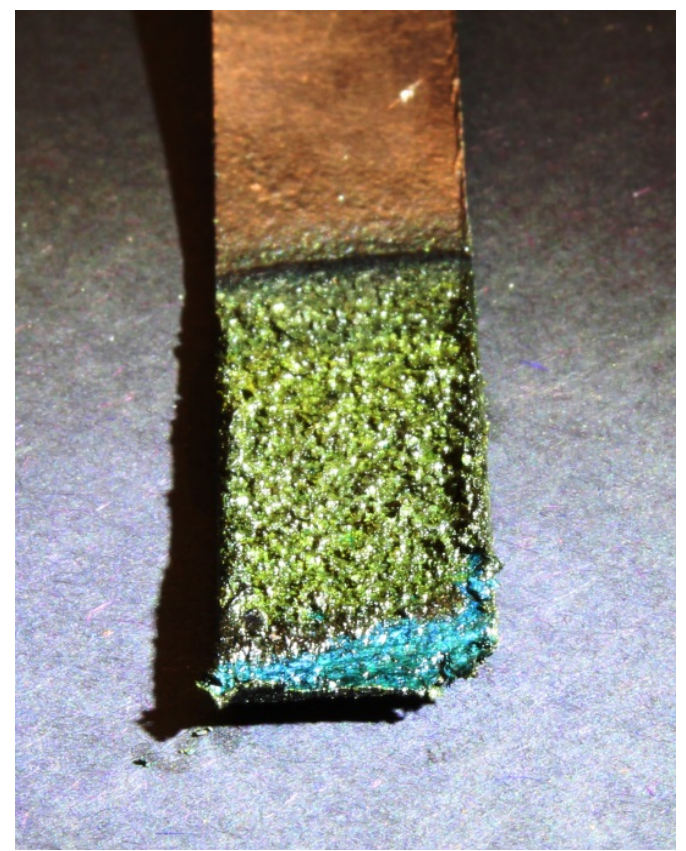

Figure 11. Graphite foil after about 30 minutes of electrolysis in the organic electrolyte. The graphite is superficially strongly oxidized, which is expressed by a yellowing. The interior of the graphite foil shows a deep blue color, indicating the presence of the GIC

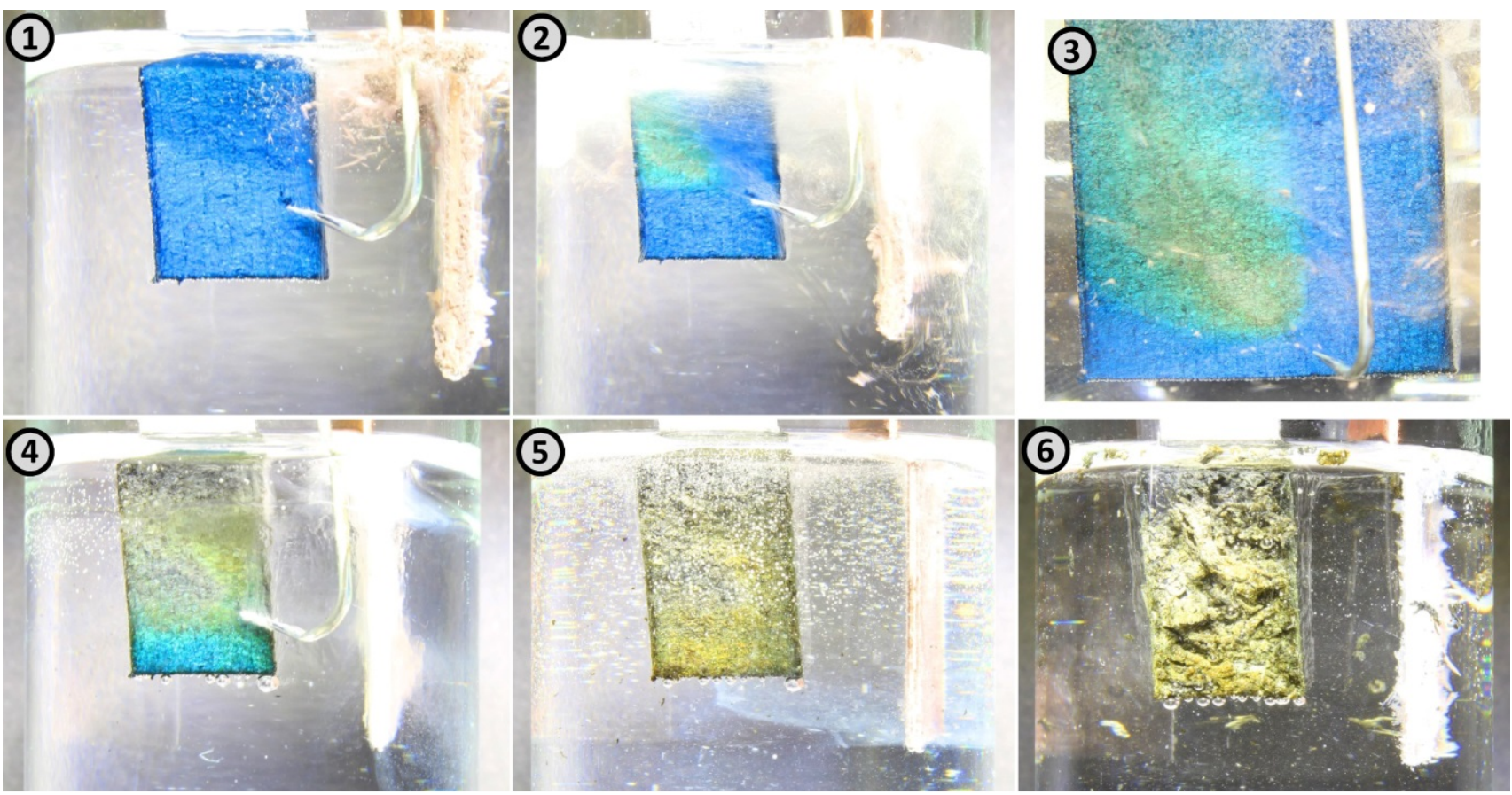

Figure 12. Oxidation of graphite by targeted spraying of the blue GIC with water. Image 1: Blue graphite intercalation compound. Image 2 \& 3 : Spraying the GIC with water. Color change due to the strong oxidation of graphite. Image $4 \&$ 5: The gradual mixing of the organic electrolyte with water oxidizes the entire graphite surface. Image 6: After 5 minutes of electrolysis, exfoliation takes place on the graphite foil, whereby large yellow flakes break off 


\subsection{The Electrochemical Synthesis of Yellow Graphene Oxide in a One-step Process}

The observations described above suggest that it is possible to realize the synthesis of yellow graphite oxide in a one-step process. To test this, we chose the same setup, but pre-mixed the organic electrolyte with a certain amount of water $(2 \mathrm{ml}$ of water to $40 \mathrm{ml}$ of organic electrolyte). If the processes actually occur simultaneously, the gray graphite foil would have to turn yellow soon after applying the voltage.

In a complex series of experiments, a ratio of 4 moles of organic solvents to one mole of water has proven to be particularly suitable.

Immediately after application of 10 volts, the graphite foil does not take on a rich blue, but acquires a turquoise color (see Figure 13-2). The turquoise appears to be due to an overlay of the deep blue GIC and the already oxidized yellow surface. After about 10 seconds, a weak gas evolution begins on the graphite foil. This is oxygen that results from electrochemical decomposition of the water. At the same time, the graphite foil assumes a yellow color. After about 3 minutes, exfoliation occurs due to the evolution of gas, with yellow graphite oxide being split off. Within 20 minutes, the entire graphite foil is converted to graphite oxide.

These observations confirm the findings from the previous experiment. With a suitable mixing ratio of organic and aqueous electrolyte, the process of intercalation and oxidation proceed simultaneously.

For the mechanism of this parallel intercalation and oxidation, we have developed the following working hypothesis. In the anhydrous organic electrolyte, GIC can be achieved by the intercalation of solvated perchlorate ions. In the one-step synthesis set-up, there is a large amount of organic solvent and a small amount of water. It is assumed that the perchlorate ions are surrounded by a heterogeneously mixed solvation shell, which consists of a relatively large amount of organic molecules and a small amount of water molecules. The turquoise color shows that the formation of the GIC also works with this composition of the solvate shell.

$$
x \mathrm{C}+\mathrm{ClO}_{4}{ }^{-}(\mathrm{solv}) \rightarrow \mathrm{C}_{x}{ }^{+}\left(\mathrm{ClO}_{4}{ }^{-}(\mathrm{solv})\right)+x e^{-}
$$

The entrained water molecules are electrochemically decomposed and ensure, by the processes described above, the formation of the oxygen-containing functional groups. The perchlorate ions thus lose in the course of the intercalation their entrained water molecules. The (now anhydrous solvated) perchlorate ions can later intercalate deeper into the interior of the graphite and continue to contribute to the formation of the GIC. Further perchlorate ions again introduce water into the graphite foil. As a result, the GIC forms in a continuous process, which is then immediately converted to the highly oxidized graphite oxide.

In this experimental set-up, the water content is also the determining factor. If too much water is added to the organic electrolyte, increased gas evolution and faster exfoliation occur. However, the exfoliated particles do not assume the desired yellow color. It can be assumed that, with a higher water content in the solvate shell, the very water-prone graphite intercalation compound can no longer form stably or it dissolves immediately.

$$
\mathrm{C}_{\mathrm{x}}{ }^{+} \mathrm{ClO}_{4}{ }^{-}+\mathrm{e}^{-} \rightarrow \mathrm{C}+\mathrm{ClO}_{4}{ }^{-}
$$

As a result, the oxidation processes based thereon cannot proceed and the highly oxidized graphite oxide does not form.

As soon as the graphite foil is completely decomposed, graphite oxide is then deposited on a filter paper by using a Büchner funnel and cleaned with $200 \mathrm{ml}$ of distilled water. This frees the graphite oxide from the organic electrolyte. Subsequently, the graphite oxide can be transferred into an aqueous suspension again (compare Figure 14-1).

Due to the large number of oxygen-containing functional groups, the van der Waals interactions between the individual oxidized graphene layers are already strongly attenuated. Already by bathing for 10 seconds in an ultrasonic bath, many graphene oxide layers can be separated and the solution turns yellow (see Figure 14-3). After another 30 minutes of ultrasonic bath, most graphene oxide layers have separated. After the larger aggregates have settled to the bottom, a homogeneous and transparent graphene oxide solution is formed (see Figure 14-4).
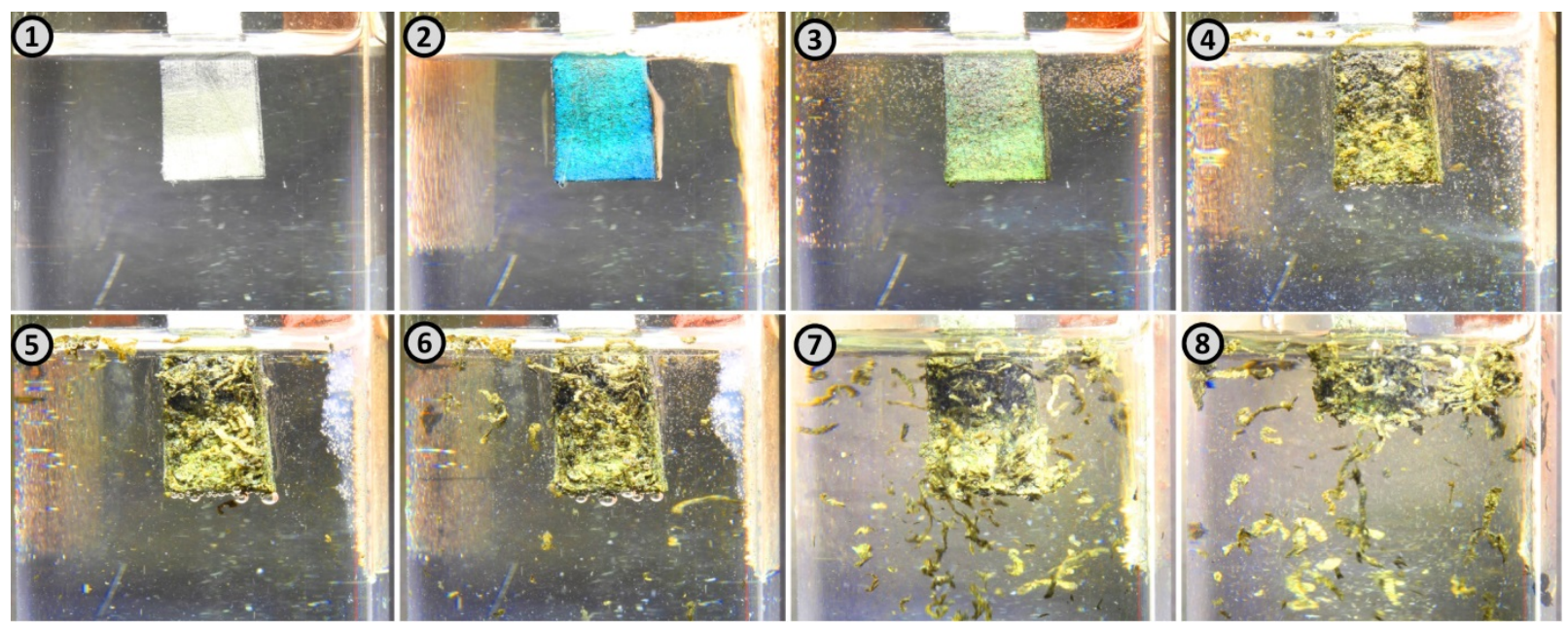

Figure 13. Synthesis of highly oxidized yellow graphite oxide in a one-step process. Image 1: Graphite foil. Image 2: Formation of the Stage-1-GIC, incipient gas evolution at the electrode. Image 3: Yellowing due to the oxidation of the graphite. Image 4-8: Oxidation of the graphite in the further course of the reaction after 3 minutes, 5 minutes, 7 minutes, 15 minutes, 20 minutes 

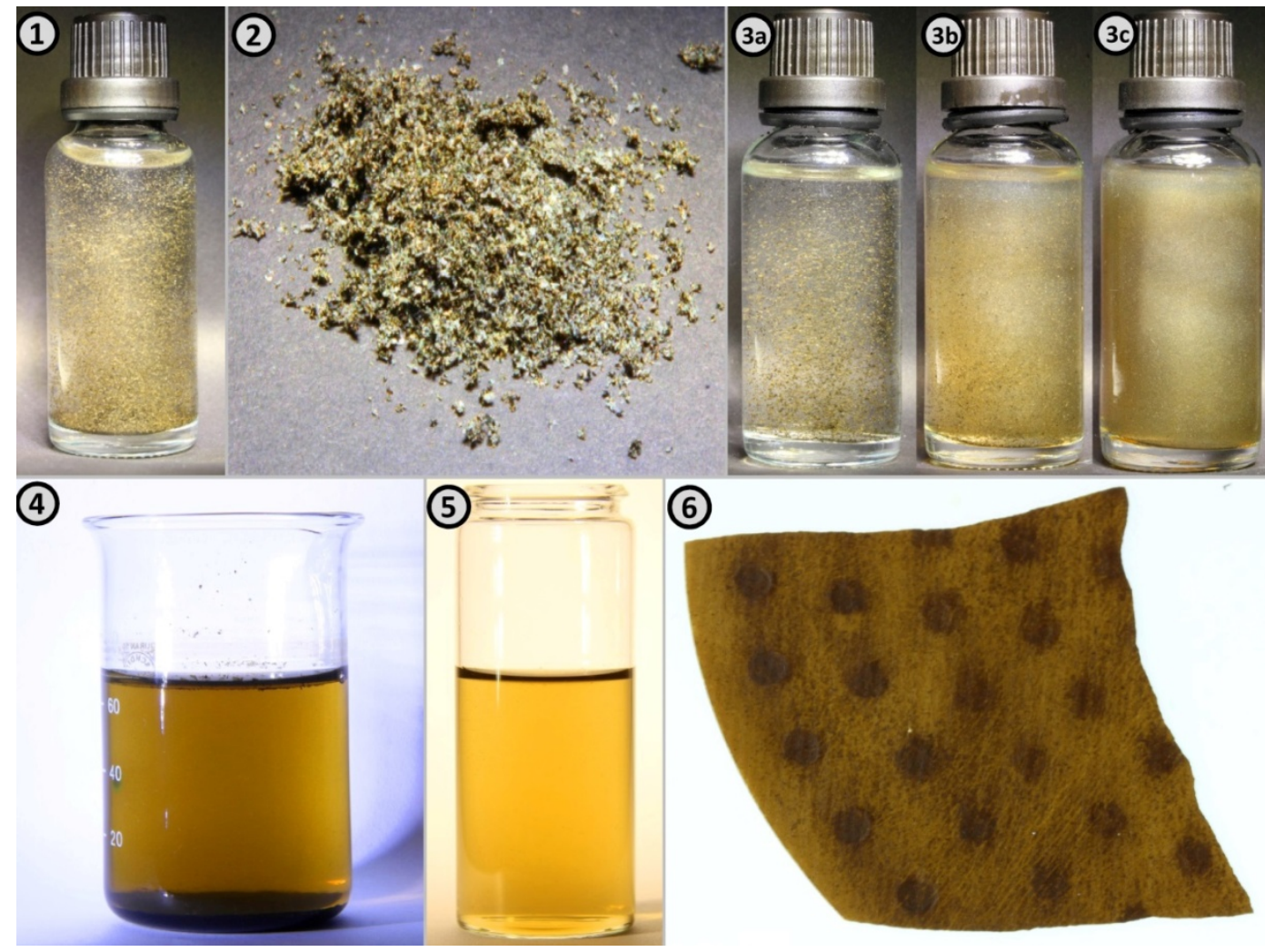

Figure 14. Image 1: Graphite oxide in aqueous solution. Image 2: Dried graphite oxide. Image 3: Influence of the ultrasonic bath. $3 \mathrm{a}$ : after 0 seconds, 3b: after 10 seconds, 3c: after 2 minutes. Image 4: Formation of the graphene oxide solution after the heavier particles have settled. Image 5: Graphene oxide solution. Image 6: Graphene oxide sucked on filter paper (pore size $200 \mathrm{~nm}$ )

Graphene oxide can be reduced to graphene by adding a reducing agent (e.g. sodium dithionite) to the graphene oxide [21].

This reaction shows the great didactic advantage of highly oxidized graphene oxide. Pupils can observe the reduction of graphene oxide to graphene by a color change from yellow to black. Furthermore, an important basic concept of chemistry education, the structure-property principle, can be impressively demonstrated with this experiment. The addition of the reducing agent reduces the polar graphene oxide to non-polar graphene. If individual graphene molecules floating in the solution collide, it is possible that Van der Waals interactions may arise, causing the molecules to accumulate. Depending on the time, the microscopically small graphene molecules aggregate to an increasingly larger structure, which can be seen macroscopically $[23,24,25,26]$.

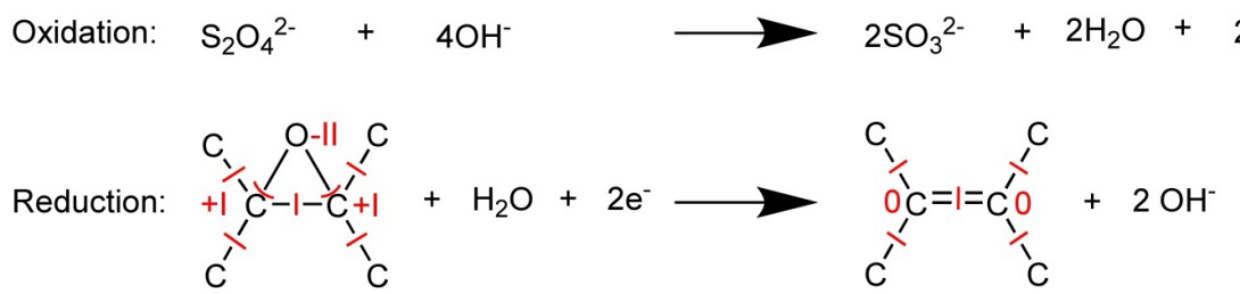

Figure 15. Reduction of an epoxy group by sodium dithionite [22]
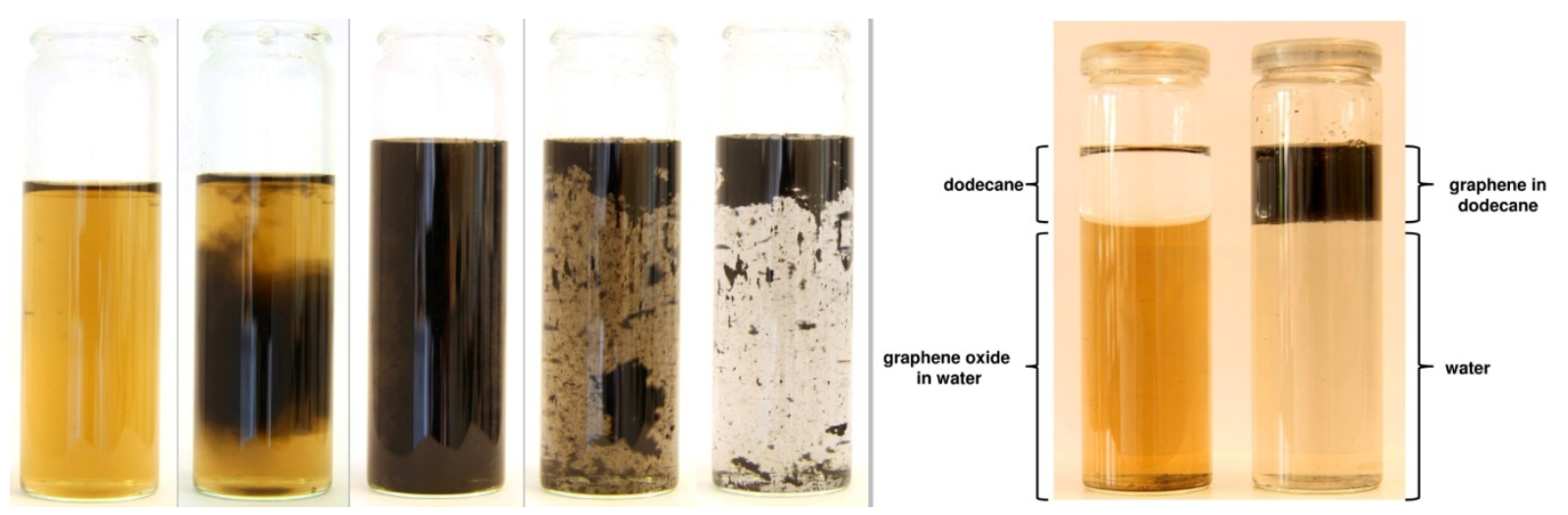

Figure 16. Left: Reduction of graphene oxide to graphene by the addition of an aqueous sodium dithionite solution. The graphene layers form van der Waals interactions and a graphite-like structure is created. Right: By shaking, the non-polar graphene can be transferred into a non-polar phase 
The non-polar graphene can easily be converted to a non-polar solvent, for example dodecane. For this purpose, the aqueous phase in which the graphene is located, is covered with a non-polar solvent and the vessel is shaken. For comparison, it is convenient to carry out the same experiment before adding the reducing agent. The polar graphene oxide particles prefer the polar medium and remain in the aqueous phase even after shaking.

\section{Conclusion}

The synthesis of graphene proceeds via the intermediate graphite oxide. The results show that highly oxidized graphite oxide can be synthesized in a one-step electrochemical process. This method differs fundamentally from current synthesis methods in terms of hazard potential, speed of synthesis and simplicity, which is why it is ideally suited for school and university education. In this method, an organic electrolyte is used to prepare the blue graphite intercalation compound. The oxidant used is water. This method does not pose a risk of explosion, as is the case with the Hummers' method. The use of organic electrolyte is harmless. It cannot cause burns, and the organic solvents used can be mixed well with water. For this reason, the product can be cleaned quickly, inexpensively, and in an environmentally-friendly way.

The one-step method has several advantages over the electrochemical two-step method. First, the synthesis is much easier to carry out. Second, in the process described, the formation of the highly oxidized graphite oxide begins as soon as the graphite foil is immersed in the electrolyte and a voltage is applied. Due to the fact that the production of the yellow graphite oxide begins immediately, this process is faster than previously known. Third, in this process, the important processes run parallel to each other. Through the use of a larger graphite foil, the production and thus the yield can be scaled up as desired, which is why this process could be of interest for technical application as well. The weak van der Waals interactions in the graphite oxide are overcome by a short ultrasonic bath to give graphene oxide. The duration of the ultrasonic bath determines the content of monolayers.

By chemical reduction, graphene oxide was converted to graphene. Simple experiments can be used to gain insights into the characteristics of graphene oxide and graphene. These experiments are ideal for demonstrating basic concepts of chemistry education.

\section{References}

[1] Lau, C. N., Bao, W., Velasco, J. (2012). Properties of suspended graphene membranes. Materials Today 15/6, 238-245.

[2] Geim, A. K., Novoselov, K. S. (2007). The rise of graphene. Nature Materials 6/3, 183-191.

[3] Larciprete, R., Fabris, S., Sun, T., Lacovig, P., Baraldi, A., Lizzit, S. (2011). Dual path mechanism in the thermal reduction of graphene oxide. Journal of the American Chemical Society 133/43, 17315-17321.

[4] Kumar, P. V., Bardhan, N. M., Tongay, S., Wu, J., Belcher, A. M., Grossman, J. C. (2014). Scalable enhancement of graphene oxide properties by thermally driven phase transformation. Nature chemistry $6 / 2,151-158$.

[5] Chua, C. K., Pumera, M. (2014). Chemical reduction of graphene oxide. A synthetic chemistry viewpoint. Chemical Society reviews 43/1, 291-312.

[6] Boehm, H. P., Eckel, M., Scholz, W. (1967). Untersuchungen am Graphitoxid V. ber den Bildungsmechanismus des Graphitoxids. Z. Anorg. Allg. Chem. 353/5-6, 236-242.

[7] Hummers, W. S., Offeman, R. E. (1958). Preparation of Graphitic Oxide. Journal of the American Chemical Society 80/6, 1339.

[8] Brodie, B. C. (1859). On the Atomic Weight of Graphite. Philosophical Transactions of the Royal Society of London 149, 249-259.

[9] Staudenmaier, L. (1898). Verfahren zur Darstellung der Graphitsäure. Berichte der deutschen chemischen Gesellschaft 31/2, 1481-1487.

[10] Pei, S., Wei, Q., Huang, K., Cheng, H.-M., Ren, W. (2018). Green synthesis of graphene oxide by seconds timescale water electrolytic oxidation. Nature communications 9/1, 145.

[11] Santhanam, R., Noel, M. (1998). Electrochemical intercalation of cationic and anionic species from a lithium perchlorate-propylene carbonate system - a rocking-chair type of dual-intercalation system. Journal of Power Sources 76/2, 147-152.

[12] Schnyder, B., Alliata, D., Kötz, R., Siegenthaler, H. (2001) Electrochemical intercalation of perchlorate ions in HOPG. An SFM/LFM and XPS study. Applied Surface Science 173/3-4, 221-232.

[13] Tian, Z., Yu, P., Lowe, S. E., Pandolfo, A. G., Gengenbach, T. R., Nairn, K. M., Song, J., Wang, X., Zhong, Y. L., Li, D. (2017). Facile electrochemical approach for the production of graphite oxide with tunable chemistry. Carbon 112, 185-191.

[14] Beck, F., Jiang, J., Krohn, H. (1995). Potential oscillations during galvanostatic overoxidation of graphite in aqueous sulphuric acids. Journal of Electroanalytical Chemistry 389/1-2, 161-165.

[15] Besenhard, J. O., Fritz, H. P. (1983). Elektrochemie schwarzer Kohlenstoffe. Angewandte Chemie 95/12, 954-980.

[16] Parvez, K., Wu, Z.-S., Li, R., Liu, X., Graf, R., Feng, X., Mullen, K. (2014). Exfoliation of graphite into graphene in aqueous solutions of inorganic salts. Supporting Information. Journal of the American Chemical Society 136/16, 6083-6091.

[17] Liu, J., Poh, C. K., Zhan, D., Lai, L., Lim, S. H., Wang, L., Liu, X., Gopal Sahoo, N., Li, C., Shen, Z., Lin, J. (2013). Nano Energy 2/3, 377-386.

[18] Hofmann, U., Frenzel, A. (1930). Quellung von Graphit und die Bildung von Graphitsäure. Ber. dtsch. Chem. Ges. A/B 63/5, 1248-1262.

[19] Dau, H., Limberg, C., Reier, T., Risch, M., Roggan, S., Strasser, P. (2010). The Mechanism of Water Oxidation. From Electrolysis via Homogeneous to Biological Catalysis. ChemCatChem 2/7, 724-761.

[20] Besenhard, Fritz (1975). Über die Reversibilität der elektrochemischen Graphitoxydation in Säuren. Zeitschrift für anorganische und allgemeine Chemie 416, 106-116.

[21] Zhou, T., Chen, F., Liu, K., Deng, H., Zhang, Q., Feng, J., Fu, Q. (2011). A simple and efficient method to prepare graphene by reduction of graphite oxide with sodium hydrosulfite. Nanotechnology 22/4, 45704.

[22] Sun, L., Yu, H., Fugetsu, B. (2012). Graphene oxide adsorption enhanced by in situ reduction with sodium hydrosulfite to remove acridine orange from aqueous solution. Journal of hazardous materials 203-204, 101-110.

[23] Martinez, C. R., Iverson, B. L. (2012). Rethinking the term "pi-stacking". Chem. Sci. 3/7, 2191.

[24] Zhao, W., Fang, M., Wu, F., Wu, H., Wang, L., Chen, G. (2010). Preparation of graphene by exfoliation of graphite using wet ball milling. J. Mater. Chem. 20/28, 5817.

[25] Yang, X., Zhu, J., Qiu, L., Li, D. (2011). Bioinspired effective prevention of restacking in multilayered graphene films: towards the next generation of high-performance supercapacitors. Advanced materials (Deerfield Beach, Fla.) 23/25, 2833-2838.

[26] Fan, Z.-J., Kai, W., Yan, J., Wei, T., Zhi, L.-J., Feng, J., Ren, Y.-M., Song, L.-P., Wei, F. (2011). Facile synthesis of graphene nanosheets via Fe reduction of exfoliated graphite oxide. ACS nano 5/1, 191-198. 